Tom Davis (2010). Complexity as Process: Complexity-inspired approaches to composition. Organised Sound, 15, pp 137-146 doi:10.1017/S1355771810000130

Published article found at http://dx.doi.org/10.1017/S1355771810000130

Copyright (C) Cambridge University Press 2010

Published online: 06 July 2010

\title{
Complexity as Process: Complexity-inspired approaches to composition
}

\section{Tom Davis ${ }^{\mathrm{a} 1} \underline{\mathrm{c}}$}

${ }^{a 1}$ Poole House, Talbot Campus, Bournemouth University Bournemouth, BH12 5BB, UK

\begin{abstract}
This article examines the use of Complexity Theory as an inspiration for the creation of new musical works, and highlights problems and possible solutions associated with its application as a compositional tool. In particular it explores how the philosophy behind Complexity Theory affects notions of process-based composition, indeterminacy in music and the performer/listener/environment relationship, culminating in providing a basis for the understanding of music creation as an active process within a context. The author presents one of his own sound installations, Cross-Pollination, as an example of a composition inspired and best understood from the philosophical position as described in Complexity Theory.
\end{abstract}

Correspondence:

c1 E-mail: tom@tdavis.co.uk

1. Introduction

In Umberto Eco's 1959 article 'The Open Work' (Eco 1989), he discusses the link between the contemporary scientific views of the day and the structuring of artistic forms. He contrasts the scientific view of the medieval world, with its fixed hierarchy of preordained orders and closed single conception of reality, with the world as described by Einstein's science - in which time and space are co-dependent, and multiple instances of reality collapse upon viewing. As Eco notes, such a change in worldview is evident through a comparison of the music of each age, a contrast evident in a comparison between medieval plainsong and the indeterminate compositions of John Cage and Stockhausen. Since Eco's article in the late 1950s there has been a rise in a new kind of scientific thinking, that of Complexity Theory. This article seeks to address how this new form of thinking about the world has permeated musical thinking of today, acting as inspiration for the structuring of new music. This article thus begins by sketching out the main concepts behind Complexity Theory, concentrating on the philosophy inspired by this science and a notion of emergence as relevant to an observer. It outlines some common problems associated with the application of Complexity Theory as a compositional tool and goes on to examine notions of process in experimental music from this perspective. It contrasts top-down and bottom-up approaches to composition, looking at the employment of environmental context as a tool for indeterminacy. The article finishes by 
presenting the author's interactive sound installation Cross-Pollination as an example of a composition that embodies this philosophy.

\section{Complexity Theory}

Complexity Theory is a branch of science that considers the complicated many-bodied systems that lie on the edge of chaos; systems that exist between the predictability of classical science, as exemplified by Newton's linear mechanics and the mathematical instability of Chaos Theory. With its roots in the systems theory of the 1960s and links to Cybernetics and Artificial Intelligence, Complexity Theory describes the special behaviour of many-bodied systems to spontaneously self-organise into higher-level structures. The defining characteristic of these self-organising properties is that they are not imposed externally but rather emerge as an internal property of the system. One example that is described by Steven Johnson in his book emergence (Johnson 2002) is that of the organisation of an ant colony. In the chapter The Myth of the Ant Queen, Johnson describes how the ants make collective group decisions such as where to bury their dead, where to forage for food and how many ants should be on guard duty, through individual ant-to-ant (chemical) interaction. In this way, rather than solving problems with a hierarchical command system, decisions emerge through low-level interaction between group members. The group intelligence of the colony is greater than the sum of intelligence of the individual ants and can be considered an emergent property of the interactions between them. Such emergent structures are a feature of all complex systems and are formed within the system through interactions between the systems components. They can be considered as new and novel structures, not immediately obvious from a examination of the system in a pre-emergent state. Such systems are resistant to reductive analysis, in that a reductive view of them cannot account for the emergence of structure as it considers the 'entirety as the sum of the single parts it is composed of' (Bertuglia and Vaio 2005: 273). Thus it is impossible to experience this organisation just by considering each single element in turn; rather, one needs to take a holistic view of the system and consider it in its entirety. Such a view of reality presents a very different view of the world to that which is described by the linearity of classical mechanics. For example, Laplace stated it would be possible to determine the state of the whole universe by considering each entity as a separate entity; that as long as we had enough knowledge about a system we would be able to predict the outcomes of the system. In contrast to this, in complex systems exhibiting emergence we have states spontaneously self-organising into other structures. The causal powers affecting these states are not external hierarchical powers but rather are an exploration of internal stable states, reductive top-down analysis of the emergent properties does not yield results; rather, we have to take a 'bottom up' approach to understanding such systems.

In Complexity Theory it is held that emergent structures are new and novel structures that appear through interaction; however, just how new and novel these structures have to be to be classed as emergent has long been the subject of philosophical scrutiny. A presentation of the full philosophical discussion is outside the scope of this article; however, it is widely held that these many distinctions fall broadly into two fundamentally distinguishable concepts, those of epistemological and ontological emergence (O'Connor and Wong 2006). These two formations of the concept of emergence are delineated by the strength of the definition of the metaphysical and ontological status of the emergent properties themselves. Ontological emergence concerns itself with the formation of fundamentally new emergent properties, for example ontological emergentists argue that human consciousness can be described as an emergent property of the brain. In contrast to this, epistemological emergence relies on the 
notion of emergent states not being predictable from their pre-emergent structures. This notion of predictability is an interesting one as it implies the presence of an agent that is doing the prediction. The ability to predict emergent states changes from person to person and so relies on a personal subjective view of emergence. Thus, such definitions of epistemological emergence can be argued to be observer dependent. Emergence in this construction can be termed 'emergence relative to an observer'. As such predictive emergent states do not require any fundamentally new structures to appear, defining a system as emergent in this context relies on new structures forming in the perceptual systems of an observer. New and novel states emerge through a user's changing perception of the system, and the level of complexity they experience is related to their complexity as a person.

This subjective construction of the world suggested by Complexity Theory can also be contrasted with that of classical science. Classical science relies on a world ready to be sampled by an objective observer, a world that can be separated into its component parts that then can be modelled and predicted from an objective, rational viewpoint. Complex systems, however, cannot be separated in this way; rather, they are constructed through the interactions of their many constituents. They interact with their context to form and re-form, to co-evolve with their environment. A recognition that complex systems do not exist in isolation, but rather are defined in conjunction with other complex systems, highlights the interconnectivity and interdependence of all elements in the creation of reality. Complex systems suggest there is no objective standpoint from outside the system from which to view reality. They thus outline a more complicated relationship with an observer, challenging ideas of subjectivity and addressing issues of how, and why we interact with the world.

\section{Musical Processes}

Complex systems present a number of exciting avenues to explore from an artistic perspective, not least the promise of the ability to outperform the designer, to create new and novel structures that cannot be predicted by the elements of their construction. However, they also throw up a number of challenges to the artist. As emergent properties are by their very definition unpredictable in nature, the processes needed to generate complex behaviour are hard to determine. To negate this problem, composers working in this scenario often employ processes known to produce complex results, for example flocking or swarm algorithms. Such processes, however, are extra-musical, often being drawn from Artificial Intelligence, or engineering-based research. There is no guarantee that such algorithms applied to music are going to make musical or aesthetic sense. Also, if, as I have argued, these emergent structures are observer dependent and arise in the perceptual faculties of an observer, careful thought has to be given to link between these emergent properties and sound. In fact, I argue that there needs to be a musical connection between the emergent structures that are produced by these processes and their rendition in sound. This relationship between the process used to create the music and the music itself is worth further examination.

I see this concern for an employment of perceptible process to be similar to the concerns evidenced by a consideration of Steve Reich's compositional method. Reich in his article Music as a Gradual Process (Reich 2004) stated that he was interested in processes that can be heard happening throughout the sounding music. For Reich it is important that the process itself is evident whilst listening to the music; in other words, it is something that is perceptible to the listeners. He contrasts his own employment of process with that of composers in the serial tradition, whom he accuses of having no audible connection between process and content. For example, Hamman writing about Iannis Xenakis' 1957 piece 
Archorripsis, in which the music is composed via a mapping process of four different probability distributions to musical characteristics (time, space, timbre and glissando speed), states that the material arises from an 'intrusion of technique' (Hamman 2004: 121). In this conception of music creation musical form is constructed from a position extraneous to music, the sonification of parameters generated by external code. It is an understanding of music construction that is akin to an objective top-down perspective, a position outside of the music in which to make rational decisions delineated by cold scientific code.

In contrast to this, I think Reich is striving for an employment of process that can be heard directly as artefacts in the music; processes which themselves have an audio element, that require no mapping between algorithm and sound. Reich states ' $[\mathrm{w}]$ hat I am interested in is a compositional process and a sounding music that are one and the same thing' (Reich 2004: 305). It is best perhaps to take an example of Reich's own music to explain what he means by this. Let us consider Reich's piece Pendulum Music (1968), which he himself describes as his 'ultimate process piece' (Reich 2007). In this well-known piece, 2, 3, 4 or more microphones are suspended over loudspeakers. These microphones are all pulled back and released together such that they generate feedback whilst swinging over the loudspeakers. The forthcoming structure of the sound is formed by the change in phase of the oscillations of the microphones. In this piece there is a direct correlation between the physical process and the generation of sound; the music is literally formed by the process. It is the process. The music and the process are both inherently physical acoustical processes articulated in sound, such that the structure and the surface of the piece are inseparable. If we employ Hamman's definition of technique as a notion most commonly understood as a 'means - conceptual or technical - by which things get produced' (Hamman 2002: 2), we can see in this instance that the distinction between the technique used to produce the 'things' and the 'things' themselves have collapsed, such that there is now no distinction between technique and product. There is no distance between the technique (the process) used to create the music and the music itself. Such a collapse between process and product allows for an examination of the product in which the process itself can become the object of investigation. Allowing the listener direct access to the process of music creation provides an insight into how the algorithm functions in the generation of sound and hopefully, by extension, an appreciation of the complexity of the work.

I think it is worth making a distinction between what I see as two different approaches to process-based composition: top-down and bottom-up approaches. I see top-down approaches to process-based composition as an imposition of structural or timbral decisions from extraneous means: the application of externally based code; abstracted, algorithmic procedures forming the basis of the music. In contrast, in bottom-up approaches there is a tighter link between the process and the musical product. There is no mapping of data to music or the sonification of a pre-existing algorithmic process; rather, the process itself is a musical one. This tighter link has the effect of letting the listener hear the process as a musical process and creates a situation that is conducive to them perceiving the emergent structures through sound. I am not saying that process-based music is the only music in which structures form in the perceptual processes through listening; instead, that music such as Reich's is a limiting case of such an exploration of process. In a scenario in which we are looking to make people aware that they are in the moment of perception, pieces that are pared down to this and this only, that have a discernible connection between the process we are trying to convey and the sound we are hearing, have a better chance of success.

\section{Indeterminate Processes}


The second of the problems facing composers working with structures from Complexity Theory is that of designing a system that should surprise the designer. Taking the examples of Reich's and Xenakis' music mentioned earlier, one could argue that there is a lack of true novelty or progression within these forms of process-based music. What then would add some true indeterminacy to the work? What would give rise to multiple instances of reality, the novelty and surprise of the emergent structures found in Complexity Theory?

In Eco's article 'The Open Work' in which he introduces the concept of the same name, he describes open works as 'works which are brought to their conclusion by the performer at the same time as he experiences them on an aesthetic plane' (Eco 1989: 169); that is, in the act of performance. Eco employs Stockhausen's Klavierstuck XI as an example of such a work. This composition asks the performer to choose, from a single large sheet of paper of note groupings, which groupings to play in which order. The instrumentalist's freedom is in the construction of the structure of the piece. Eco likens it to working with the 'components of a construction kit' (Eco 1989: 169). He reminds us that this definition of 'open works' is not to be confused with the term openness as used by the aesthetic theorists, in which a work is open 'on account of its susceptibility to countless different interpretations which do not impinge on its unadulterable specificity' (Eco 1989: 169). Eco thus makes the distinction between works open in a performative sense, and those that could be considered only open in an interpretive sense. Eco draws parallels between this performatively open work and the physics of Einstein. He links the lack of a linear causal system in complex behaviours with a similar 'general breakdown of causation' in composition, with the composer bequeathing previously compositional decisions, to the performer or to chance. Eco also posits a link between 'multivalue logics' in which several views of reality can be said to be true at once, (for example the wave-particle duality of light) and the poetics of the open work: the freedom of the performer and the 'discontinuity' of contemporary physics.

For John Cage, however, Klavierstuck XI is not indeterminate enough. He challenges the idea that this piece is indeed indeterminate with respect to its performance. Cage believes that as the piece contains the twelve tones of an octave and a regularity of beat (within a contemporary definition), the performer will be lead to give the piece all the conventional aspects of European music (Cage 1958: 178). Cage goes as far as to say '[i]n the case of Klavierstuck XI the use of indeterminacy is in this sense unnecessary since it is ineffective. The work might as well have been written in all aspects determinately' (Cage 1958: 178).

For Cage, the purpose of indeterminacy is to bring about an unforeseen situation; to give the composer and performer freedom to create 'experimental music', music where the outcome is not foreseen or predictable, and ' $[\mathrm{t}] \mathrm{o}$ remove the work from the body of European musical conventions'. Cage is not looking for a way of making music that is ambiguous in its interpretation, but is employing indeterminacy as a way of implementing a 'specificity of listening' (LaBelle 2006: 9). Cage is seeking a movement towards an extra-musical situation, away from music, towards sound, 'from the symbolic and representational (music) to the phenomenal and non-representational (noise)' (LaBelle 2006: 9). Cage's concept of the indeterminate work does not expect us to relate to a sound in any one way, but places sound in a context, which allows us to relate to it in an increasingly personal way. As LaBelle notes Cage is moving away from an overtly musical framework for composition to a more contextual framework that relates the performance and the performers to their cultural and environmental context. 
Eco draws a link between these indeterminate forms of composition and Pousseur's 'field of possibilities', describing the notion of a field as a 'complex interplay of motive forces', 'a configuration of possible events' and of 'possibility' as 'the discarding of a static, syllogistic view of order, a corresponding devolution of intellectual authority to personal decision, choice and social context' (Eco 1989: 170), thus challenging the hierarchical external power of the composer and instead suggesting an approach to composition in which the composer sets up a situation within which it is possible to interact and form is constructed indeterminately through low-level interaction. Such an open consideration of composition has direct parallels with Complexity Theory but also the contextually and philosophically similar standpoint of 'art is life', with its implied reference to Happenings, Fluxists and the Environmentalists. Such movements had a common philosophy in seeking to include the environment and everyday objects in their art-based events, the opening up of boundaries between the performers and audiences and the recognition of natural environmental spaces as places for artistic exchange of complex creative potential. These artistic practices can be characterised by their performances, where form emerges through the interaction of many disparate elements, where form is not imposed from the top, but emerges through interactions amongst the constituents. The coming together of people and events in this manner is the meeting of a complex system of interactions with other complex systems: the interaction of the complexity of reality with the complexity of the human.

I suggest that this recognition of the importance of space, place and situation in composition can be employed as a strategy for escaping from generatively closed compositions. The creation of works that are open to environmental interaction, that embrace and utilise their context, is a way of injecting some indeterminacy back into the system. In this way the system is open to interaction and thus can be considered as just one part of a complex ecology of music-making.

\section{Ecological Processes}

Jack Burnham, speaking in the context of system-based art, makes the assertion that ' $[\mathrm{t}] \mathrm{he}$ specific function of modern didactic art has been to show that art does not reside in material entities, but in relations between people and the components and their environments' (Burnham 1968: 32). Thus, if we consider the art created in environments as part of the ecosystem that includes the environment, perhaps we can create systems that exhibit a conceptual richness in what they convey and they way in which they are perceived. This approach to art would be in contrast to Walter Benjamin's 'aura' of the object and its associated authority (Benjamin 1936), but more in common with Agnostino di Scipio's idea that 'sonic art is a tension towards a limit - that is, it is about the merging of the qualitative and the quantitative, in an inextricable exchange between the primacy of perception and the primacy of modern reason' (di Scipio 2002: 23).

Bernard notes the tendency of Minimalist art for the content not to reside in the art object itself, but rather 'in its physical setting or in viewer's responses' (Baker $\underline{1988}$, quoted in Bernard 1993: 117). In this scenario the real-time experiences of the viewer become important; the art object becomes something temporal in nature, something that evolves over time.

This seems to be a relevant stance for process-based music, where the art object and technique are one and the same, interdependent in form and function. In di Scipio's words there is a 'healthy confusion between matter and form as a radical stance concerning the 
indissoluble intertwining of nature and culture, object and subject' (di Scipio 2002: 23). Di Scipio likens this indissoluble intertwining with the Heisenberg uncertainty principle, the fact that knowing information about one aspect of a particle affects how much information we can know about another. He presents this as an example of the problems of dealing with anything in a truly objective manner, and speculates that in fact ' $[\mathrm{t}] \mathrm{o}$ deal with something is to transform it, so the essence of 'it' is a matter of speculation' (di Scipio 2002: 23).

Burnham discusses the same things:

The computer's most profound aesthetic implication is that we are being forced to dismiss the classical view of art and reality which insists that man stand outside of reality in order to observe it, and, in art, requires the presence of the picture frame and the sculpture pedestal. The notion that art can be separated from its everyday environment is a cultural fixation [in other words, a mythic structure] as is the ideal of objectivity in science. It may be that the computer will negate the need for such an illusion by fusing both observer and observed, 'inside' and 'outside.' It has already been observed that the everyday world is rapidly assuming identity with the condition of art. (Burnham 1969: 119)

The above assertion rings true with Cage's view that all sound is music and that there is a blurring of the distinction between art and life. For example, Cage's 4'33", 1952, arguably his ultimate indeterminate piece, is also about the music of everyday sounds. In fact there is no distinction between the two.

In his essay, Happenings in the New York Scene (Kaprow and Kelley 2003), Kaprow describes the many disparate elements of what could construct a 'Happening'. The list includes dragging of ice and stones, blue lights flashing, nude women throwing spinach, muslin telephone booths, projected slides and movies, wine jugs, record players, microphones, iron barrels, ropes, breathing sounds on speakers, lawn mowers, and more (Kaprow and Kelley 2003: 15). The materials of the happenings were always different, but their structure had a common ethos. Their form was open ended and fluid. They employed chance in their construction and there was a breakdown in boundaries between audience and performers. Kaprow states that even if you entered the space only intending to fulfil the role of a spectator you often found yourself caught up in the creation of art after all (Kaprow and Kelley 2003: 15).

Such ecological approaches to composition and an understanding of compositional process from such a perspective seem to have the most elements akin to complex theories. These approaches explore issues of site-specificity, liveness and audience interaction in their work and take into account the active and situational notion of encounter that is manifest specifically in sonically led environments. As Owen Green (2006: 5) points out, in di Scipio's work there is a 'structural coupling of humans, technology and their environment. The environment is not something we control, but interact with, and it exerts reciprocal effects on us; technology is not a means to exercise control, but again something we interact with that affects the course of our actions.' This lack of attempt to control the environment has a lot in common with the 'open composition' methods employed by Cage. The environment and the structure in the environment have been carefully crafted by the artist, but the mode of interaction within this crafted situation is left open and not prescribed.

Such a conception of music sits well with Simon Waters' discussion of the notion of a 'performance ecosystem', a conception of music performance that does not rely on a 
performer/instrument distinction but rather highlights the 'ambiguity [and] fragility of the performer instrument articulation' (Waters 2007). In this notion there is a mutability between environment and viewer, environment and installation, installation and viewer, such that the environment and the viewer can be understood as becoming part of the generative process themselves, each as closely linked to the evolution of the structure. The performance ecosystem highlights the relationships between the physicality of the body, the instrument, and the environment. Such a conception of music construction highlights music as an activity that can be 'understood as [a] dynamical complex of interacting situated embodied behaviours' (Impett 2001: 1).

If however, we consider that the boundaries between environment, listener and music have collapsed, we can ask: what is it that the composer is actually designing in this instance? The composer is acting as a mediator between a physically embodied complex system and a more philosophical notion of an embodied interaction of the user. He or she does this through carefully constructing the user's engagement within the situation. (For a detailed account of philosophical embodiment see Dourish 2004: 126). The composer controls the experience of the user, the environment of interaction: he or she structures the moment of encounter.

\section{A note on agency}

In working with complexity we need to create many-bodied systems in which agents interact. Also within the concept of a performance ecosystem, a level of agency is prescribed to all elements of the situation. However, to what extent can simple mechanical processes that make up installations be called agents? Dennett, in his article Intentional Systems (Dennett 1971), describes an 'intentional stance' of prescribed intentionality one can take towards systems in order to help us better interpret or predict their actions. For example, in trying to understand what a complex being like a human would do next, it would be quite natural to use folk psychology, or an assumption based on our knowledge of their intention to predict their behaviour. Dennett argues that such a stance can also be applied to machines. He employs the example of a chess-playing machine that is so complicated that it has become impossible to predict its outcome even by knowing every element of its programming. In this scenario it is much easier to assume the machine will make the best move it can within the rules and goals of chess than it is to predict its move from a knowledge of its constituent parts.

This notion of ascribed intentionality is interesting from an artist's point of view since it involves the relationship between humans and technological systems. Nell Tenhaaf, in her article 'Art Embodies A-Life: The VIDA Competition' (Tenhaaf 2008), draws our attention to a pervasive tendency to attribute agency to technological devices spontaneously without consideration. This attribution of agency by an observer is similar in character to an adoption of Dennett's intentional stance. Dennett himself comments on the application of intentionality as a 'convenient, explanatory, pragmatically necessary action' (Dennett 1971: 92). Dennett also draws to our attention problems associated with the application of intentionality to systems that may not strictly exhibit intention. He states such problems can be easily overcome since he does not state that his intentional systems 'really have beliefs and desires', just that we can explain and understand them better 'by ascribing beliefs and desires to them'. It is this relationship with systems that is of interest from an artistic point of view: a construction of intentionality that is understood as something that is applied by an observer and thus is observer specific. Such a concept of a unique user-specified intention highlights a developing relationship with technology rather than just a controlling of it. This in turn points 
towards a situation where there can be a co-evolution of humans with technologies, where ' $[\mathrm{b}]$ oth the humans and machines become actants who have agency and inform each other, resulting in composite societies of agents that include both natural and artificial members' (Tenhaaf 2008: 13).

\section{A sharing of social space}

In an ecological concept of music-making a level of agency is present or attributed to environmental setting, installation components and viewers alike. All the elements can be considered as situated and embodied, able to co-evolve with their environmental context. Within this ecological concept of agency, agents in music creation can be considered to be coupled with their context, generating a shared embodied meaning through all being part of the same environmental space. As previously mentioned, these ideas originally came to the fore when considering Minimalist sculpture, so they are easiest to address from the position of sonic practices that involve the direct interaction of a listener embodied in a space: for example, such listening scenarios as the concert-going listener or, more obviously, the context of interactive sound installation where the listener is able to determine his or her physical relationship to the piece through moving and engaging with it on his or her own terms.

In the seventies and eighties, we lived in a society of spectacle, in the nineties in the society of participants, and we are now developing a 'society of interactors'. (De Oliveira, Oxley and Petry 2003: 106)

De Oliveira et al. draw a distinction between spectacle, participants and interactors, citing Bourriaud's notion of a relational aesthetics as a conception of art 'in which objects are catalysts generating communicative processes' (De Oliveira et al. 2003: 106). The distinction they are trying to draw between participation and interaction employs the term interaction not as we commonly think of it, but as 'social interstice': a focusing on inter-human relations, sociability, art defined in the 'realm of human interactions and its social context, rather than the assertion of an independent and private symbolic space' (Bourriaud 1998: 14). In such a conception of art, communication is the key: as interactors are becoming a part of the work, their presence is required to give it meaning. As an example of his ideas, Bourriaud introduces us to a work by Félix González-Torres Untitled (Arena) that was presented at a one-man show at the Jennifer Flay Gallery in 1993. In this installation González-Torres installed a quadrilateral bounded by switched-on light bulbs. Portable music players were provided to the visitors so that they could dance noiselessly under the fairy lights. Bourriaud draws our attention to the notion that the encounter with the work is more temporal in nature, not eliciting so much a sense of space, as experienced through encounters with Minimal Art, but an encounter that is governed by time, 'Time of manipulation, understanding, decisionmaking, going beyond the act of "rounding off" the work by looking at it' (Bourriaud 1998: 59).

\section{Complexity as Process}

The installation Cross-Pollination (figure 1) is an example of one of a series of works created by the author to explore compositional methods driven by an understanding of Complexity Theory. It aims to guide the ear of the listener to the emergent musical structures that arise from interactions between the installation's constituent parts. Its design and construction are guided by a study of Complexity Theory, and the author's concerns with the listener 
becoming aware of his or her perception of emergent structures through interaction with the piece. This piece aims to create a generative system where form is not imposed from the top down, but is created by interactions amongst the constituent parts. This system is designed to be ecologically open in order to add a level of indeterminacy to the work such that form is not fixed within a boundary but rather is open to the full complexities of the environment.

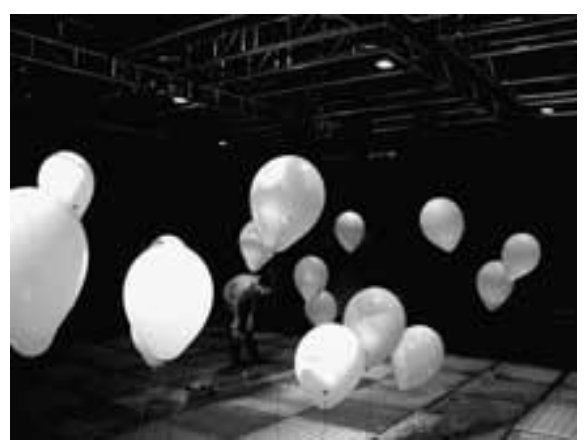

Figure 1

Cross-Pollination setup in SARC's Sonic Laboratory.

\section{$\underline{\text { Low resolution version High resolution version }}$}

In order to create a 'society' of interacting agents from which emergent structures can arise, this installation is constructed out of twenty physically distinct agents. Each agent is constructed from a one-metre balloon, four metres of piano-wire, a piezo transducer, a threeVolt motor and a motor controller. Each balloon is connected to a piano wire and on each balloon there is a piezo transducer. The piezo transducers are each connected to a motor driver in such a way that if there is any sound at their balloon they will cause another motor to start spinning. These motors are set up to pluck a different piano wire, thus activating another balloon and hence another motor. The piezo transducers and motors are wired in two discrete feedback loops as shown in figure 2, with the intention that a sound at one balloon will start off a chain of feedback, ultimately reaching back to the originating balloon. Although the two feedback loops look discrete, balloons 1, 3, 5, 7 and 2, 4, 6, 8 on the diagram, since the balloons have a double function of microphone and resonator, and due to their proximity in a shared environment, it is possible for the soundings of one balloon to activate an adjacent balloon in a different feedback loop. In this way it is possible that unforeseen complex interactions can emerge, leading the installation to take on an indeterminate nature of sonic output. This cross-pollination of sound activation is further disrupted and complicated since it is possible for the balloons to be activated by any sound in the space. Hence, users walking amongst the space or interacting with the balloons, as they are encouraged to do, can disrupt and/or augment the complex patterns they are hearing. 


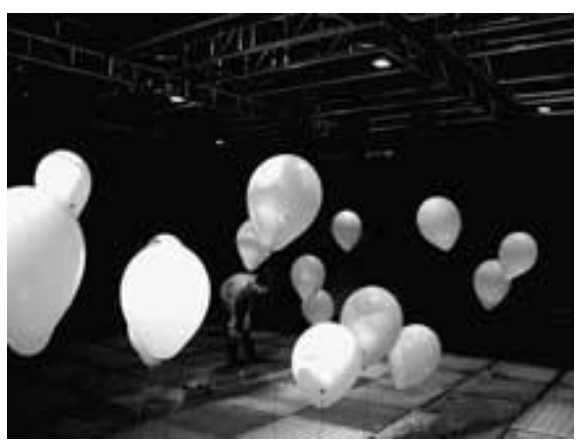

Figure 2

Schematic of outlay of agents and interactions in Cross-Pollination.

\section{$\underline{\text { Low resolution version High resolution version }}$}

This installation employs the strategies outlined in the previous sections to negate some of the perceived problems associated with working with complex systems. It attempts to side-step issues associated with the mapping algorithms from one domain to another by using a model that is intrinsically sonic in nature, attempting to create a scenario where the interactive process is directly perceptible through listening to and interacting with the piece. This is facilitated through constructing the agents so that they communicate with each other directly through sound. The piano-wire/balloon agents both 'listen' and 'speak' in aural terms with a direct, physical, acoustic connection to their environment and to each other. These agents are designed to interact with each other to form musical structures in time. These interactions are governed by the acoustic energy of one agent affecting the energy of another displaced by space, such that if an agent hears another agent making a sound it responds by making a noise. These twenty agents thus respond to each other in the space, listening and replying to each other's acoustic energy. These interactions are not hard-wired, rather they are mediated by the space and thus the position of the agents and distance from each other affects their response. This distribution in space is designed to facilitate the cross-talk of energy between feedback loops (hence the name Cross-Pollination) and also to create the sense of a completely engulfing environment within which users can bodily engage. Through the employment of an interactive process in which music and process are one and the same thing, this installation presents a scenario in which listeners can catch themselves in the moment of perception, leading the ear in the perception of emergent structures.

Since there are many agents listening from different positions there is not a linear relationship between making a noise at one point in the system and getting a sonic result at another. On touching or activating one balloon, you as an interactor have little idea of what the result is going to be, not because the physical complexity of the installation makes it impossible to predict, but because the interactivity of the constituent parts makes it much more complex than it seems. In Cage's terminology this piece is open in both a compositional and a performative sense. From a compositional perspective there exists an environment, a situation governed by rules - rules which define a field of possibilities. In addition to this 'programmed' indeterminacy, due to the interactions between the agents, emergent structures appear that are characterised by their novel and unexpected behaviour. These behaviours emerge from the bottom up, from the interactions between the agents and their environment and are thus resistant to top-down analysis. In fact, in two exhibitions of this piece the installation has fallen into unobvious patterns of interaction seemingly caused by broken or 
disrupted electronics. However, when constituent parts were removed and tested they were found to be individually working. It was only in situ, as part of a bigger complex environment of interactions that they seemed to be malfunctioning. They were instead exhibiting emergent behaviours. Cross-Pollination is also open in a performative sense. As it is an interactive installation there is no prescribed way to interact with the work. Thus users can disrupt and alter these forming emergent structures through acoustic or physical interaction with the work, becoming active participants in an ecology of music-making (figure 3).

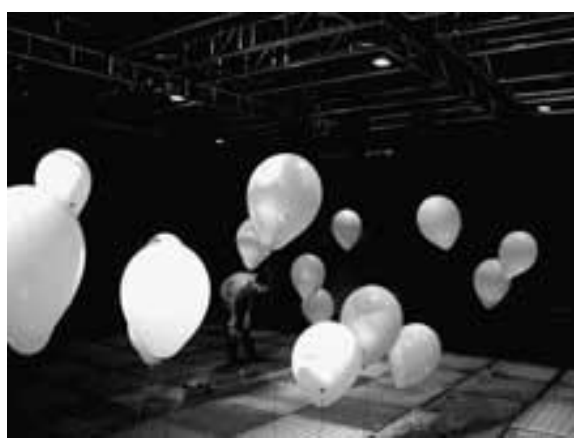

Figure 3

A participant interacting with the Cross-Pollination installation.

\section{Low resolution version High resolution version}

The piece is designed to reflect the non-reductionist ethos of Complexity Theory. It is impossible get a full understanding of the piece by considering any of the separate parts in isolation. In this piece the environment is used as an active agent, a persistent entity utilised to communicate between agents and interactors and also to shape and affect the finished sound. The installation's sound is contingent on the performance space in a very dynamic way and thus placing the same installation in a different location creates a very different result. This piece exploits the indeterminancy of these environments and is ecologically open in that every element in the system is affected by environmental variables: each element of the system has a level of agency in the construction of the piece. No part of the system has an overall control or a higher level of agency than any other. As each system interacts through the shared medium of sound there is parity between human and technological interactors. Touching a balloon creates sound, which in turn triggers a motor, which affects another balloon, which creates sound in the space that affects other balloons. Relationships between entities are not fixed or hard-wired but are open to mediation by location. There is a mutability of function of all the elements in the situation. The agents act as receptors and generators, microphones and speakers. They offer instances of non-linear interaction and give non-linear feedback. The environmental space acts as a conveyor of information, a shaper of sound, and is also an active part of the situation. The human participants act as interactors and audience, performers and listeners. There is an attribution of Dennet's notion of intentional agency to the constructs of the system. The different balloon motor pairings seem to take on intentional characteristics, being bullish or shy, noisy or quiet.

The installation embodies the connectivity of an ecology, where energy imparted in one area of the installation affects components elsewhere. When the space is populated with multiple human interactors this displacement is taken further, with the collaborative effort of musicmaking now shared between technological agents and humans. This piece thus becomes a 
way of exploring sonic interaction between a number of complex systems: the humans, the technological agents and their sonically active complex environment. There is a sharing of acoustic energy, a sociality of music-making between human and technology. Through a communication of musical ideas in performance, music is created in the social interactions within all the elements of the installation environment.

\section{Conclusion}

This article has highlighted how an understanding of Complexity Theory can be used to inform compositional choices in creative practice. It has outlined a conception of the notion of emergent structures that is observer dependent and has related this to an understanding of musical structures that sees them as subjective and timely rather than as fixed objects for empirical observation. This article has highlighted a number of challenges of working with complexity-inspired approaches to composition and has outlined a number of strategies to overcome them. Problems associated with designing a work to ensure emergent qualities are perceivable to a listener were addressed in two ways. Firstly, through an examination of use processes in music it has become apparent that there is a need for the employment of generative structures that are in themselves inherently musical, that concentrate on making emergent structures perceptible to the ear. It is this simplicity of a relationship between process and product that allows people to catch themselves in the moment of perception, to become aware that they are in the act of perceiving. Such an approach also side-steps issues associated with mapping from one process to another, therefore avoiding the situation of a sonification of a non-musical algorithm. Secondly, inspired by the non-reductionist understanding of the world suggested by Complexity Theory and a related concern for the injection of some indeterminacy into the work, the processes used are open in an ecological sense. Every element in the situation of the installation - the agents, the interactors, their shared environmental context - has a level of agency in the construction of the structure of the work and the finished product. Such a consideration of the creation of a work considers a system not in isolation, but in a situation. It is a context that recognises the specificity of listening that is contingent on your surroundings. This prescribed level of agency to every element in the system acknowledges not only the active role that every element takes in constructing the form and structure of the music, but also the fact that every element is involved in the creation of meaning.

\section{References}

- Baker, K. 1988. Minimalism: Art of Circumstance. New York: Abbeville Press. [Google Scholar]

- Benjamin, W. 1936. The Work of Art in the Age of Mechanical Reproduction. In C. Harrisson and P. Wood (eds.) Art in Theory, 1900-1990: An Anthology of Changing Ideas. Oxford and Cambridge, MA: Blackwell, 2000. [Google Scholar]

- Bernard, J. W. 1993. The Minimalist Aesthetic in the Plastic Arts and in Music. Perspectives in New Music 31(1): 86-132. [OpenURL Query Data] [CrossRef] [Google Scholar]

- Bertuglia, C. S., Vaio, F. 2005. Nonlinearity, Chaos, and Complexity: The Dynamics of Natural and Social Systems. Oxford: Oxford University Press. [Google Scholar]

- Bourriaud, N. 1998. Relational Aesthetics. Dijon: Presses du Réel. [Google Scholar]

- Burnham, J. 1968. Systems Esthetics. Artforum 7(1): 30-35. [OpenURL Query Data] [Google Scholar] 
- Burnham, J. 1969. The Aesthetics of Intelligent Systems. In E. F. Fry (ed.) On the Future of Art. New York: The Viking Press, 1970. [Google Scholar]

- Cage, J. 1958. Composition as Process: Indeterminacy. In C. Cox and D. Warner (eds.) Audio Culture: Readings in Modern Music. New York: Continuum, 2004. [Google Scholar]

- De OliveiraOxley, N., Petry, M. J. 2003. Installation Art in the New Millennium: The Empire of the Senses. New York: Thames \& Hudson. [Google Scholar]

- Dennett, D. C. 1971. Intentional Systems. The Journal of Philosophy 68(4): 87-106. [OpenURL Query Data] [CrossRef] [Google Scholar]

- Di Scipio, A. 2002. Systems of Embers, Dust, Clouds: Observations after Xenakis and Brun. Computer Music Journal 26(1): 22-32. [OpenURL Query Data] [CrossRef] [Google Scholar]

- Dourish, P. 2004. Where the Action Is: The Foundations of Embodied Interaction. Cambridge, MA: The MIT Press. [Google Scholar]

- Eco, U. 1989. The Poetics of the Open Work. In C. Cox and D. Warner (eds.) Audio Culture: Readings in Modern Music. New York: Continuum, 2004. [Google Scholar]

- Green, O. 2006. More than 'Just a Hammer': Critical Techniques in Electroacoustic Practice, SoundAsArt, 26 November 2006.

- Hamman, M. 2002. From Technical to Technological: The Imperative of Technology in Experimental Music Composition. Perspectives in New Music 40(1): 92-120. [OpenURL Query Data] [Google Scholar]

- Hamman, M. 2004. On Technology and Art: Xenakis at Work. Journal of New Music Research 33(2): 115-123. [OpenURL Query Data] [CrossRef] [Google Scholar]

- Impett, J. 2001. Interaction, Simulation and Invention: A Model for Interactive Music. In E. Bilotta, E. R. Miranda, P. Pantano and P. M. Todd (eds.) Proceedings of ALMMA 2001 Workshop on Artificial Models for Musical Applications. Cosenza: Editoriale Bios, 108-119. [Google Scholar]

- Johnson, S. 2002. Emergence: The Connected Lives of Ants, Brains, Cities and Software. London: Penguin Books. [Google Scholar]

- Kaprow, A., Kelley, J. 2003. Essays on the Blurring of Art and Life. Berkeley: University of California Press. [Google Scholar]

- LaBelle, B. 2006. Background Noise: Perspectives on Sound Art. London: Continuum International Publishing Group. [Google Scholar]

- O’Connor, T., Wong, H. Y. 2006. Emergent Properties. Stanford Encyclopedia of Philosophy. http://plato.stanford.edu/entries/properties-emergent (accessed 17 December 2007).

- Reich, S. 2004. Music as a Gradual Process. In C. Cox and D. Warner (eds.) Audio Culture: Readings in Modern Music. New York: Continuum. [Google Scholar]

- Reich, S. 2007. Steve Reich interview on Pendulum Music. http://www.furious.com/perfect/ohm/reich.html (accessed 17 December 2007).

- Tenhaaf, N. 2008. Art Embodies A-Life: The VIDA Competition. Leonardo 41(1): 615. [OpenURL Query Data] [CrossRef] [Google Scholar]

- Waters, S. 2007. Performance Ecosystems: Ecological Approaches to Musical Interaction. EMS: Electroacoustic Music Studies Network, 12th-15th June 2007. 